\title{
Principios mediáticos éticos. Guía para no seguir siendo el troglodita machirulo, blanco y occidental
}

\section{Ethical media principles. A guide not to remain the sexist, white and western troglodyte}

Fechas | En edición: 08/09/2020 - Publicación final: 01/01/2021

\section{Dr. Omar RINCÓN}

Universidad de Los Andes. Colombia. orincon@uniandes.edu.co

\section{Guía de transición ecosocial y principios éticos para nuestros medios}

M. Chaparro-Escudero; L. Espinar-Medina; Á. El MohammadianeTarbift; L. Peralta-García.

Madrid: Fragua, 2020.

274 páginas

ISBN: 978-84-7074-862-2

\section{Resumen}

La Guía de transición ecosocial y principios éticos para nuestros medios es un texto que más que leerlo lo debemos tener ahí, a la mano, porque nos es útil para diseñar y producir las mejores historias con conciencia crítica de este mundo que habitamos. Esta guía plantea soluciones desde los sentidos, el lenguaje y las narrativas a la crisis de civilización que nos tocó en destino y de la cual los medios y el periodismo son el signo deforme.

\section{Palabras clave}

Comunicación; decolonial; manual; posdesarrollo; transición ecosocial; ética periodística

\begin{abstract}
The "Ecosocial Transition Guide and Ethical Principles for Our Media" is a text that more tan reading it, we must have it at hand, because it is useful to design and produce the best stories with a critical conscience of this World we inhabit. This guide proposes solutions from the senses, language and narratives to the crisis of civilization that touched us in fate and of which the media and journalism are the deformed sign.
\end{abstract}

\section{Keywords}

Communication; decolonial; manual; postdevelopment; ecosocial transition; 


\section{Guía para no seguir siendo el troglodita machirulo, blanco y occidental}

No podemos llamar periodismo a eso que hacen muchos medios (eso del clic, el sensacionalismo y seguir a los políticos como si estos fueran sabios que en cada frase iluminan al mundo). Medios y periodismo están desnudos, los ciudadanos ya saben o deberían saber que mienten, que lo que informan no sirve para la vida diaria, que su información solo sirve a sus amos, que son las redes las que mueven la actualidad y que son Facebook, Google, Twitter y Whatsapp quienes tienen el poder de movilizar sobre la realidad cuando escapan a la manipulación del poder, incluido el de los medios convencionales. El único hecho periodístico verdadero es que la generalidad de los medios ha dejado de hacer periodismo, de preocuparse por los asuntos reales. Y le podemos echar la culpa a las redes; en parte, pero no son ellas, somos los periodistas los que convertimos a las redes en la noticia y, a la inversa, somos los periodistas los que queremos ser la noticia de redes. Somos los periodistas los que premiamos al agresivo y al bullynero sobre el razonado y con criterio. Somos los periodistas, no le echemos la culpa a la realidad. Somos los periodistas los que no nos cuestionamos nuestro oficio, nuestro colonialismo, nuestra fealdad.

El imperativo es intervenir "ese" periodismo que Pere Ortín llama \#Gágá [l] que es "un sistema opresor de dominación colonial y racista que vive de «dar voz» y utraducir» a los otros y otras -como si no fueran capaces de expresarse por sí mismos-"; ese periodismo malentendido a la "Kapuściński : moralista, misionero, jurásico y basado en consensos fosilizados". Y cómo combatirlo, Ortín dice que es "buscando fuera del periodismo", manchándonos "con lo que nos rodea, ya sea en un palacio o en el lugar más cutre del mundo. Mancharnos con la poesía, el arte contemporáneo, la filosofía, el lenguaje, la física cuántica". Combatir ese concepto de información y actualidad definida por los amos sean políticos o empresarios u oenegeros. Y, obvio, "combatir a los nuevos viejos enemigos: Amazon, Facebook, Google". Ortín apuesta por "un periodismo fronterizo, forajido, maverick, asilvestrado, que comete muchos errores pero se lo pasa bien y que trata de mancharse con la realidad". Uno que "ensaya, intenta, prueba, sondea, tantea, experimenta... se atreve. Se equivoca, lo asume, lo dice". Y apuesta por la belleza.

Otra alternativa está en este texto "Guía de transición ecosocial y principios éticos para nuestros medios", donde la propuesta es "un periodismo pausado, reflexivo, un periodismo de fluir lento, de pensar, de hablar para entender, de interpretar y de tomar decisiones no sujetas a las emociones, ni a los fervores del momento".

Un periodismo que decide que la información "no está en el hecho, sino en su memoria". Un periodismo desde y en el territorio, para y con los ciudadanos, desde y con los medios locales.

Un periodismo con otra agenda de autenticidades, ya que tiene como foco para comprender al mundo a la transición ecosocial, la perspectiva de género, las éticas LGTBI, los discursos de odio, las migraciones y grupos minorizados; para desde ahí contar y hacer rendir cuentas a la política, la economía, la justicia, el deporte, la cultura, el mundo.

Para hacer posible esta propuesta de un periodismo otro desde abajo y con los ciudadanos, este texto de Chaparro, Espinar, Tarbift y Peralta (Madrid, Fragua, 2020), que toma como punto de partida el libro: Claves para repensar lo medios y el mundo que habitamos. La distopía del desarrollo (Chaparro, 2015, Bogotá, Desde Abajo), hace primero una crítica profunda al periodismo de la actualidad, a la comunicación extractivista y al modelo de desarrollo que nos ha llevado al hambre. No se queda en la crítica, sino que plantea que solo desde "el común" se puede imaginar una transición socioecológica del cuidado, el vínculo, la convivencia entre todos con lo no humano y lo espiritual. Y ese "común" implica dejar de orientar la acción política y económica en el yopitalismo (ese capitalismo del yo que se expresa en el consumo) para imaginarnos desde el territorio como "único espacio real de las transformaciones y de decisiones que conducen a la soberanía ciudadana". Y es ahí donde la comunicación, los medios y los periodismos deben actuar para desvelar las discriminaciones, incluir narrativamente esas "realidades silenciadas, negadas e ignoradas".

La portada lo dice todo de este libro. Uno, que es una guía para comprender la mutación ecosistémica que estamos atravesando. En este sentido busca ser algo práctico, algo que sirva para diseñar, hacer y evaluar medios en esa transición de hábitos de producción y consumo. Aquí sirve mucho porque nos explica en qué consiste el nuevo lenguaje de la política, donde hay experiencias que ponen en acción esos conceptos y cómo se puede narrar desde ahí.

Dos, la guía es sobre los principios éticos que atraviesan los modos de contar de los medios; obvio, aquí la ética no es moralizar ni ejercer maniqueísmos o buenaondismos, ni catastrofismos, sino una ética política sobre el estilo de vida de nuestra sociedad; por eso, plantea "una serie de principios éticos narrativos relacionados con la práctica del periodismo". 
Tres, una figura de caracol multicolor contiene las palabras que organizan el horizonte político-teórico del texto. Y ahí se plantean tres ejes: el del contar: comunicación-relatos-narrativas; el de inspirar: territoriossoberanías-diversidad; el del intervenir: pluriverso-decrecimiento-decolonialidad. Estos conceptos constituyen el horizonte de sentido de todo el texto y que son explicados filosófica y prácticamente en la guía.

La utilidad de este libro es múltiple:

* Sirve como una crítica a la comunicación, los medios y el periodismo; pero es más útil, como la propuesta para hacer una comunicación y un periodismo otro en clave de responsabilidad ecosistémica. Y esto se concreta en un manual de estilo periodístico que puede consultar al final.

* Es una genial crítica al concepto y experiencia del desarrollo, el cambio social y la sostenibilidad, que muta en una propuesta sobre cómo sobrevivir a la catástrofe sin perder el estilo del humano-consumo.

* La guía es un mapa conceptual y práctico para que los periodistas e interesados en la mutación social que habitamos podamos adentrarnos en la pepa de los conceptos políticos más potentes de nuestro imaginario social: lo ecosocial, la perspectiva de género, las deconstrucciones de lo LGTBI, los discursos de odio, las migraciones, los grupos minorizados, los menores y las discapacidades.

El lector podrá leerlo como quiera, usarlo según sus necesidades, y tal vez no lo lea, pero siempre estará ahí a la mano para cuando esté diseñando o produciendo una historia y no quiera pasar por machirulo, blanco y occidental ignorante que no se ha enterado que la actualidad es diversa e intercultural. O sea, esta guía le permitirá no quedar como un troglodita y, aún mejor, hacer mucho más político el oficio de diseñar y contar historias en los medios.

\section{Referencias}

Abad, M. (2020). Periodismo Dadá:;A la hoguera con el periodismo GaGá! Yorokobu.es. https://www.yorokobu.es/periodismo-dada/ 